Akiba, Y. 25

Andreeva, J. 7

Beauchamp, G.K. 1

Cho, C.H. 19

de Araujo, I.E. 32

Ferreira, J.G. 32

Hasumura, M. 13

Kaunitz, J.D. 25

Khropycheva, R. 7

Kitamura, A. 37
Ko, J.K.S. 19

Kondoh, T. 32

Mennella, J.A. 1

Nakamura, E. 13

Ren, X. 32

Torii, K. IV, 7, 13, 37

Tsurugizawa, T. 37

Uneyama, H. 7, 13

Yeckel, C.W. 32

Zolotarev, V. 7

\title{
Subject Index Vol. 83, Suppl. 1, 2011
}

Acid sensor 25

Adaptive cytoprotection 19

Afferent sensory neurons 19

Autonomic reflex 37

C57BL6/J mice, weight gain 32

Carbonic anhydrase 25

Chemosensing 13

Child 1

Dietary glutamate 7

Endocrine cell 13

Flavor 1

Food 1

Functional magnetic resonance imaging 37

Gastric mucosa 13, 19

- pouch 7

Glutamate 13

G-protein-coupled receptors 25

Hypothalamic-pituitary-adrenal axis 19
Imprinting 1

Indirect calorimetry 32

Infant 1

Innervation 7

Low- and high-fat diets 32

Luminal nutrient 25

Mild irritants 19

Monosodium L-glutamate 37

- glutamate 32

Postingestive effect 37

Prostaglandins 19

Secretion 7

Smell 1

Somatostatin 13

Taste 1

Umami-tasting compounds 32

Vagus nerve 19, 37

Vanilloid receptor 25

(C) 2011 S. Karger AG, Basel 